\title{
Treatment of chronic recurrent dislocation of temporomandibular joint by autologus blood injection
}

\section{Syed Sayeed Ahmed, Md. Kalim Ansari}

Department of Oral and Maxillofacial Surgery, Dr. Ziauddin Ahmed Dental College, Aligarh Muslim University, Aligarh 202002, India. Correspondence Author: Prof. Syed Sayeed Ahmed, Department of Oral and Maxillofacial Surgery, Dr. Ziauddin Ahmed Dental College, Aligarh Muslim University, Aligarh 202002, India. E-mail: drssahmed@msn.com

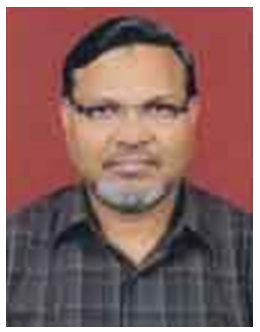

Prof. Syed Sayeed Ahmed, MDS, MFDS RCPS (Glasgow), is recipient of TC White Visiting Scholarship of Royal College of Physicians and Surgeons of Glasgow, Glasgow, Scotland, UK; Commonwealth Fellowship by Association of Commonwealth Universities, UK; and visited Sammelweis University, Budapest, Hungary under Indo-Hungarian Educational Exchange programme. His main areas of research are maxillofacial trauma, neurological diseases of maxillofacial region and microbiology of odontogenic and diseases of temporomandibulr joint.

\begin{abstract}
Aim: The aim of this study was to evaluate the efficacy of autologus blood injection in the management of recurrent temporomandibular joint (TMJ) dislocation. Methods: A total of 11 patients, 4 males, 7 females, mean age of 58.6 years and suffering from recurrent dislocation of TMJ, were included in the study. In all the patients the procedure included anesthesia- local or sedation, arthrocentesis which was followed by autologous blood injection in the upper joint cavity. The peri-articular tissues were also infiltrated with autologous blood. Post procedure advice included restricted mouth activity and liquid diet for a month. Results: The results indicate that success rate of treatment of recurrent dislocation of $\mathrm{TMJ}$ is $72.8 \%$ which can be considered as impressive. The recurrence was noticed in $27.2 \%$ cases after one year follow up. Conclusion: Autologus blood injection is an effective, simple, non-invasive, and safe procedure for treatment of recurrent dislocation of TMJ and can be performed on outpatient basis.
\end{abstract}

Key words:

Subluxation; recurrent dislocation; arthrocentesis; temporomandibular joint; autologous blood

\section{INTRODUCTION}

Sometimes during normal opening of the mouth the condylar head of the mandible moves forward anterior to the articular eminence but still remains within the capsule of the joint. This is termed as dislocation which may be classified as acute, chronic and recurrent. Recurrent dislocation of temporomandibular joint

\begin{tabular}{|l|l|}
\hline \multicolumn{2}{|c|}{ Access this article online } \\
\hline Quick Response Code: & Website: \\
\hline & http://parjournal.net \\
\cline { 2 - 2 } & DOI: \\
\hline
\end{tabular}

(TMJ) may require professional help for reduction or occasionally it may be self reducing. This condition is characterized by inability to close the mouth once mouth is wide open. When this is self reducible or self reducing - it is referred to as subluxation. In contrast, luxation or dislocation is a condition requires professional help to return the joint to its normal position.

This is an open access article distributed under the terms of the Creative Commons Attribution-NonCommercial-ShareAlike 3.0 License, which allows others to remix, tweak and build upon the work non-commercially, as long as the author is credited and the new creations are licensed under the identical terms.

For reprints contact: service@oaepublish.com

How to cite this article: Ahmed SS, Ansari MK. Treatment of chronic recurrent dislocation of temporomandibular joint by autologous blood injection. Plast Aesthet Res 2016;3:121-5.

Received: 30-10-2014; Accepted: 08-04-2016 

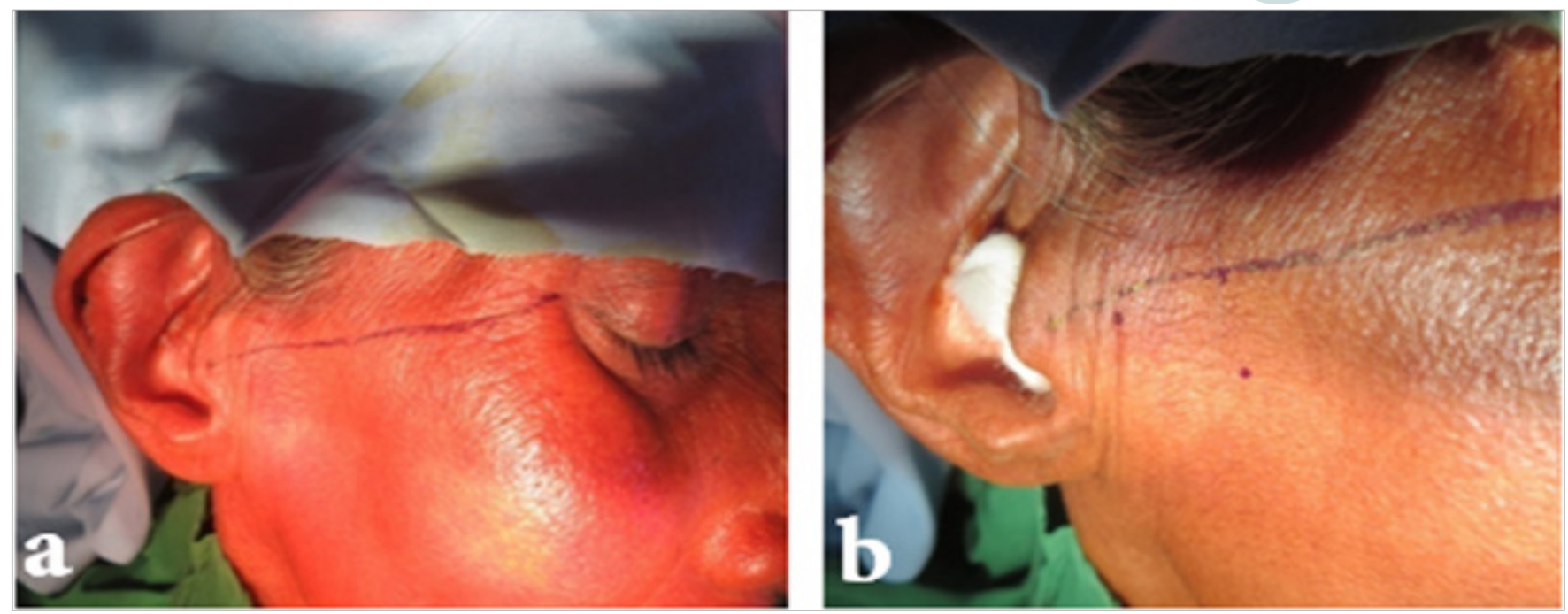

Figure 1: (a) Showing markings for canto-tragal line; (b) two points marking for double puncture arthrocentesis followed by blood injection at the posterior mark
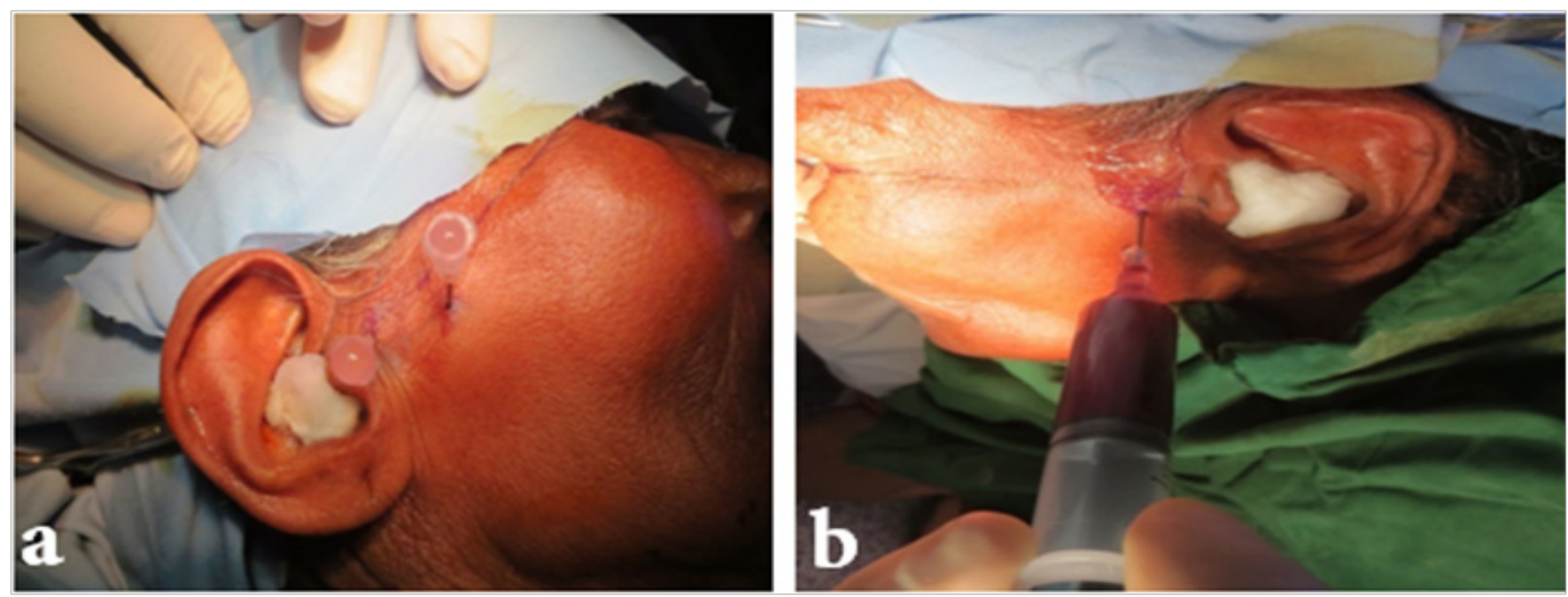

Figure 2: (a) Arthrocentesis using two point puncture in temporomandibular joint technique; (b) autologous blood injection

Table 1: Age, gender, duration of disease, frequency and treatment outcome

\begin{tabular}{|c|c|c|c|c|c|c|c|c|}
\hline No. & Age & Gender & $\begin{array}{l}\text { Duration of } \\
\text { disease in } \\
\text { months }\end{array}$ & $\begin{array}{l}\text { Frequency of } \\
\text { dislocation per week }\end{array}$ & $\begin{array}{l}\text { Average } \\
\text { frequency } \\
\text { per week }\end{array}$ & $\begin{array}{l}\text { History of previous } \\
\text { treatment }\end{array}$ & $\begin{array}{l}\text { Period of } \\
\text { follow up in } \\
\text { months }\end{array}$ & Post treatment recurrence \\
\hline 1 & 43 & $M$ & 12 & $3-4$ & 4.2 & - & 24 & No \\
\hline 2 & 45 & $\mathrm{~F}$ & 6 & $3-5$ & & - & 18 & No \\
\hline 3 & 48 & $\mathrm{~F}$ & 12 & $4-6$ & & - & 24 & No \\
\hline 4 & 51 & M & 24 & $2-3$ & 4.4 & $\begin{array}{l}\text { Yes, bandage } \\
\text { to restrict mouth } \\
\text { opening }\end{array}$ & 12 & No \\
\hline 5 & 53 & $\mathrm{~F}$ & 5 & $5-6$ & & - & 16 & Yes \\
\hline 6 & 55 & M & 36 & $3-4$ & & $\begin{array}{l}\text { Yes, IMF, } \\
\text { medications }\end{array}$ & 18 & No \\
\hline 7 & 52 & $\mathrm{~F}$ & 18 & $4-6$ & & - & 26 & Yes \\
\hline 8 & 56 & $\mathrm{~F}$ & 12 & $5-6$ & & $\begin{array}{l}\text { Yes, medications, } \\
\text { bandage to restrict } \\
\text { mouth opening }\end{array}$ & 24 & No \\
\hline 9 & 62 & $\mathrm{~F}$ & 36 & $3-4$ & 4.3 & - & 18 & No \\
\hline 10 & 67 & $\mathrm{~F}$ & 12 & $4-6$ & & - & 20 & No \\
\hline 11 & 73 & M & 48 & Innumerable & - & $\begin{array}{l}\text { Yes, injections and } \\
\text { medications }\end{array}$ & 24 & Yes \\
\hline
\end{tabular}

IMF: intramaxillary fixation

Chronic recurrent dislocation of TMJ (RTMJD) may occur as results of routine activity of life, like excessive yawning, laughing loudly, vomiting or opening mouth too wide for eating, due to trauma like blow on the chin while mouth is open, injudicious use of mouth gag during general anesthesia or excessive pressure on the mandible during dental extraction, and is characterized 
Table 2: Showing recovery after treatment and complications

\begin{tabular}{|c|c|c|c|c|c|c|c|c|c|}
\hline \multirow[t]{2}{*}{ No. } & \multirow{2}{*}{$\begin{array}{l}\text { Maximum } \\
\text { mouth opening } \\
\text { preoperative } \\
\text { in } \mathrm{mm}\end{array}$} & \multicolumn{6}{|c|}{ Episodes of dislocation during period of observation } & \multirow{2}{*}{$\begin{array}{l}\text { Maximum } \\
\text { mouth } \\
\text { opening in } \mathrm{mm}\end{array}$} & \multirow[t]{2}{*}{ Complications } \\
\hline & & $\begin{array}{l}\text { 1st and 2nd } \\
\text { week }\end{array}$ & 3rd week & 1st month & 3rd month & 6th month & 1 year & & \\
\hline 1 & 38 & - & - & - & - & - & - & 38 & Mild pain \\
\hline 2 & 39 & Yes & - & - & - & - & - & 38 & - \\
\hline 3 & 42 & - & - & 1 & 1 & - & - & 40 & - \\
\hline 4 & 39 & - & - & - & - & - & - & 38 & Mild pain \\
\hline 5 & 40 & Yes & Yes & Yes & Yes & Yes & Lost follow up & - & - \\
\hline 6 & 39 & & - & & & & & 36 & - \\
\hline 7 & 37 & Yes & Yes & Yes & Yes & Yes & Yes & Not applicable & Recurrence \\
\hline 8 & 38 & - & - & - & - & - & - & 34 & - \\
\hline 9 & 39 & - & - & - & - & - & - & 36 & Mild pain \\
\hline 10 & 42 & - & - & - & - & - & - & 40 & \\
\hline 11 & 46 & Yes & Yes & Yes & & & $\begin{array}{l}\text { Treated by } \\
\text { surgical } \\
\text { means }\end{array}$ & - & Recurrence \\
\hline \multicolumn{6}{|c|}{ Mean mouth opening (preoperative) 39.9} & \multicolumn{4}{|c|}{ Mean mouth opening $37.2 \mathrm{~mm}$ (postoperative) } \\
\hline
\end{tabular}

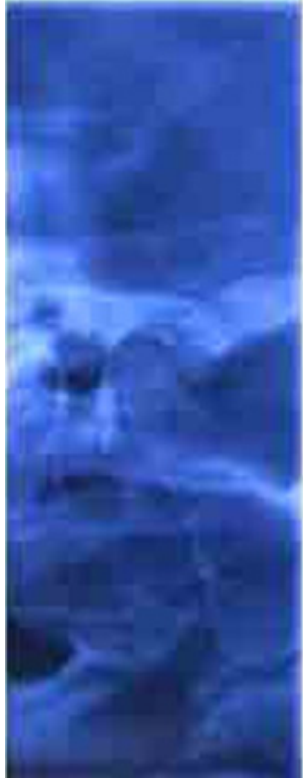

A

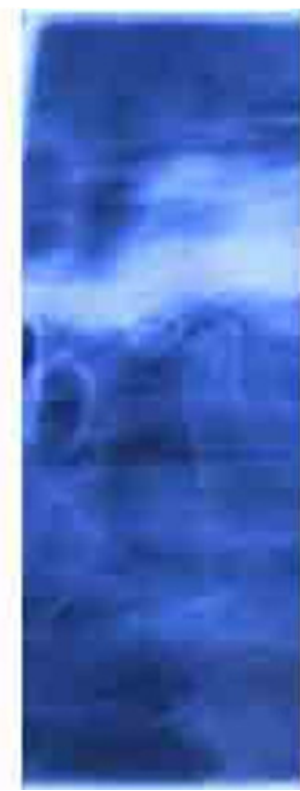

B

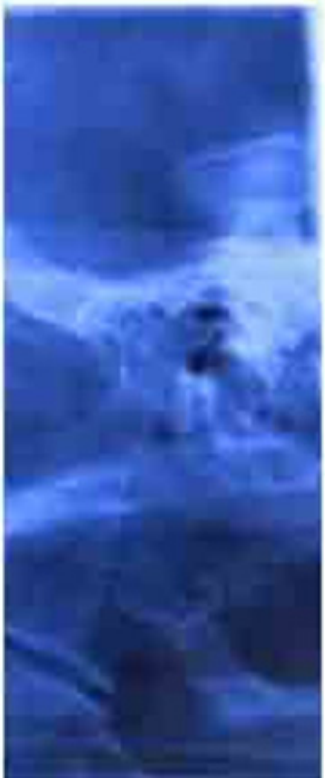

C

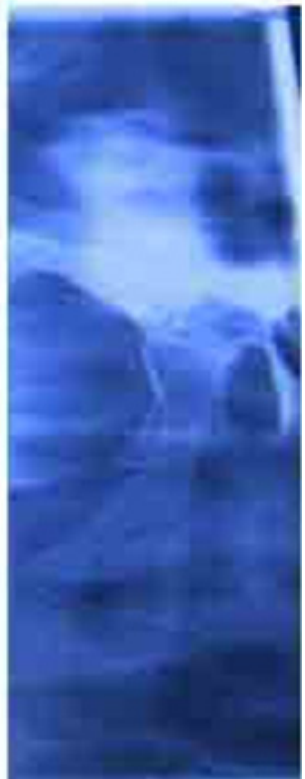

D

Figure 3: Temporomandibular joint view showing pre and post autologous injection radiographs. A: Pre-injection left side; B: post autologous blood injection; C: pre-injection right side; D: post autologous blood injection

by gagging of molar teeth, anterior open bite or long face appearance. The etiology of recurrent dislocation is not known, however, the pathogenesisis involves soft tissues or bone. Involvement of tissues is related with weakness of ligaments or laxity of capsule. ${ }^{[1]}$ At bone level, abnormal size of eminence or shallow glenoid fossa, may another contributing factor. Certain systemic diseases like Parkinson's disease, epilepsy, Ehler Danlos syndrome and antipsychotic drugs which may cause extra pyramidal reactions, have also been attributed as predisposing factors.

Recurrent dislocation induces traumatic effects on all the structures of joint including disc, ligament and capsule. Various surgical and non-surgical and surgical treatments have been employed to treat chronic recurrent dislocations of TMJ but none has received universal approval, ${ }^{[2-4]}$ thus attempts are still on finding an amicable treatment of this problem.

Among conservative, nonsurgical treatment intra articular injections of sodium psyllate, sodium murrhoate and sodium decyl sulphate ${ }^{[5]}$ have been used with limited success. Brachmann ${ }^{[6]}$ was first to use intrarticular injection of autologous blood for treatment of RTMJD. Schulz ${ }^{[7]}$ re-described the technique for the treatment with good results. However, still very little is known about the use of autologous blood in this condition, we decided to document our experiences of intrarticular injections of autologous blood in RTMJD. This technique is simple, noninvasive, and safe and can be performed under local anesthesia or intravenous sedation on outpatient basis.

\section{METHODS}

A total of 11 patients ( 4 males, 7 females) with age range between 43-73 years (mean age 58.6 years) who attended the OPD of Department of Oral and Maxillofacial Surgery, Dr. Ziauddin Ahmed Dental College and Hospital, Aligarh Muslim University, Aligarh, India with chief complaint of inability to close the mouth which very often remained open during routine activity of the 
mouth. The problem was either reduced by patient themselves, or required some professional help or was self reducing. They all had undergone conservative treatment for the condition but no significant improvement was noticed. The clinical diagnosis was confirmed by lateral view of TMJ in open and closed mouth position. In all cases, the head of condyle was found to be anterior to the articular eminence in wide open mouth position. To all the patients various treatment options were presented and only those patients who consented for intra-articulouar autologus blood injection (IABI) were included in the study. IABI was given by two point puncture technique as described by Schulz. ${ }^{[7]}$

\section{Technique}

The procedure was planned to be performed under local anesthesia using lignocaine $2 \%$ with adrenaline. The patient was asked to lie in supine position. After preparing the site with antiseptic and draping, an auriculotemporal nerve block was given on either side using. A line from middle of tragus to lateral canthus of eye was drawn on either side and a point was marked at articular fossa which was located $10 \mathrm{~mm}$ anterior and $2 \mathrm{~mm}$ inferior to this line. Second point was marked $20 \mathrm{~mm}$ anterior and $10 \mathrm{~mm}$ inferior to this canthotragal line and this line corresponds to the peak of eminence [Figure 1a and b]. Then an 18-gauge 1.5-inch long needle was inserted at the first point up to a depth of 1 inch and stabilized. Another 18-gauge 1.5-inch long needle was inserted at the second mark corresponding to articular eminence. After insertion of needle at the two points, joint lavage (arthrocentesis) was done using $10 \mathrm{~mL}$ of normal saline solution [Figure 2]. After lavage of the joint second needle was withdrawn and $4 \mathrm{~mL}$ of blood was taken from patients cubital vein and $3 \mathrm{~mL}$ was injected in the articular fossa through first needle. Then the needle was withdrawn slightly outward for 1 $\mathrm{cm}$ and another $1 \mathrm{~mL}$ of blood was injected around pericapsular tissue. The same procedure was done for the opposite side also [Figure 3]. After this an elastic bandage was applied for one week and all the patients were advised to restrict their mouth opening and to take liquid diets only. Anti-inflammatory analgesic (aceclofenec $100 \mathrm{mg}$ ) was prescribed for 3 days. Subsequent follow up was done at 1 week, 1 month and 6 months period and clinical outcomes and maximal mouth opening were noted during follow-up period.

The composition of patients and various observations pertaining to study have been shown in Tables 1 and 2 .

\section{RESULTS}

The results of study indicate that success rate of treatment of recurrent dislocation of temporomandibular joint is $72.8 \%$ which can be considered as impressive. After follow up period of one year, only 3 patients suffered from recurrence (27.2\%).

\section{DISCUSSION}

We have performed autologus blood injection in eleven patients of recurrent dislocations. The results of study have been summarized in Tables 1 and 2. At a follow up period of one year and only 3 of them suffered from recurrence. Their average maximal mouth opening also reduced from $39.9 \mathrm{~mm}$ preoperatively to $37.2 \mathrm{~mm}$ postoperatively.
Blood is injected into two regions, in the articular fossa and pericapsular tissue. The blood injection causes fibrosis and scarring in the areas of injection which stops the dislocation of condyles from recurring. However, we feel that limited mouth in initial first week is important for the success of treatment. This limitation can be achieved by TMJ bandage or intermaxillary fixation, ${ }^{[1]}$ or asking the patient to take liquid or semi solid diet with efforts of not to open wide. We have used elastic bandaging for three weeks and kept the patients exclusively on liquid diets in the first week and then soft and semisolid diet for the next two weeks to restrain the mandibular movements. After three weeks patients were advised to start mandibular physiotherapy to maintain functional mouth opening. Some workers have shown their concern about development of ankylosis and degeneration of articular cartilage after performing autologus blood injection..$^{11,2]}$ In our study, no such complications were found at whole period of follow-up. We have opinion that there is no chance of ankylosis after IABI. Chances of ankylosis are always there wherever the joint is traumatized to extent that structures within the joint capsule are damaged and there is intrarticular bleeding. Exogenous bleeding (intra-articular injection) doesn't have same effect as endogenonus bleeding. The blood simply pushes the condylar head in posterior position and helps in maintaining the position. The periarticular fibrosis, which results due to autologous blood injection supplements the forward translation of condyle which is further aided by elastic bandage, restricting the mouth opening. ${ }^{[8,9]}$

The disadvantage of the procedure is that it is a blind procedure, even then it is safe and complication free. In our study, pain was only reported complication which could be easily managed by anti-inflammatory analgesics.

Results of our study support the findings of Daif ${ }^{10]}$ who performed a comparative study of autologus blood injection in the superior joint space alone vs. superior joint space and pericapsular tissues and found higher success rate in the combined injection than the same in superior joint space alone. However, we performed clinical study using combined injection technique as it appeared much sound. Using combined technique we found success rate of $89.1 \%$ at a follow-up period of 1 year.

Various means to restrict mandibular movement have been applied. ${ }^{[11,12]}$ We used elastic bandage for one month and soft diet in our cases. It was convenient, comfortable to patient and easily adjustable.

There is no predictive indicator for success of treatment by non surgical means including autologous blood injection. However, the cases who don't respond positively in the initial 3 weeks of treatment should be considered as failure case. In such condition surgical methods should be opted.

We did not find any appreciable complications in the study. Only 3/11 (27.3\%) patients complained of mild pain which was controlled by tablet aceclofenac $100 \mathrm{mg}$ in twice daily doses and did not affect the routines of the patients. These results are in slight contrast to study of Candirli ${ }^{[13]}$ in which, 14 patients were treated with autologous blood injection and found no complications. The only serious complication was recurrence which could be noticed in 2/11 cases (18.9\%). In other words, the success rate is 
$89.1 \%$. However, in other studies, $80-85 \%$ success rate has been documented. This difference may be due to difference in sample size. Further, personal application of technique may be also an important factor. Hence further study with large sample size and long term follow-up is needed to see the actual success rate with autologus blood injection. In our study, the mouth opening after was slightly reduced which is statistically insignificant and can be clinically considered as unchanged.

In conclusion, autologus blood injection is a simple, noninvasive, cost-effective, short duration and safe procedure which can be performed under local anesthesia/IV sedation in an outpatient basis. However, the results of the present study are of limited value because of the scarce amount of patients in the series and because the technique does not allow a direct visualization of the intra-articular space of the joint.

\section{Financial support and sponsorship Nil.}

\section{Conflicts of interest}

There are no conflicts of interest.

\section{REFERENCES}

I. Sharma R. Modifications to Norman's procedure for hypermobility of the TMJ. Med J Armed Forces India 20I 2;68:23 I-5.

2. Costas López A, Monje Gil F, Fernandez Sanromán J, Goizueta Adame C, Castro Ruiz PC. Glenotemporal osteotomy as a definitive treatment for recurrent dislocation of the jaw.J Craniomaxillofac Surg 1996;24: 178-83.

3. Bakardjiev A. Treatment of chronic mandibular dislocations by bone plates: two case reports. J Craniomaxillofac Surg 2004;32:90-2; discussion 93.

4. Kummoona R. Surgical managements of subluxation and dislocation of the temporomandibular joint: clinical and experimental studies. J Craniofac Surg 2010;21:1692-7.

5. Rowe NL, Williams JL. Row and Williums Maxillofacial Injuries. London: Churchill Livingstone; 1994. p. 352-5.

6. Brachmann F. Autologous blood injection for recurrent hypermobility of the temporomandibular joint. Dtsch Zahnarztl Z 1964;15:97-102. (in German)

7. Schulz S. Evaluation of periarticular autotransfusion for therapy of recurrent dislocations of the temporomandibular joint. Dtsch Stomatol 1973;23:94-8. (in German)

8. Ungor C, Atasoy KT, Taskesen F, Cezairli B, Dayisoylu EH, Tosun E, Senel FC. Short-term results of prolotherapy in the management of temporomandibular joint dislocation.J Craniofac Surg 2013;24:4 I I-5.

9. Zhou H, Hu K, Ding Y. Modified dextrose prolotherapy for recurrent temporomandibular joint dislocation. Br J Oral Maxillofac Surg 20I4;52:636.

10. Daif ET. Autologous blood injection as a new treatment modality for chronic recurrent temporomandibular joint dislocation. Oral Surg Oral Med Oral Pathol Oral Radiol Endod 2010;109:31-6.

II. Machon V, Abramowicz S, Paska J, Dolwick MF. Autologous blood injection forthe treatment of chronic recurrent temporomandibular joint dislocation.J Oral Maxillofac Surg 2009;67: I I4-9.

12. Kato T, Shimoyama T, Nasu D, Kaneko T, Horie N, Kudo I. Autologous blood injection into thearticular cavity for the treatment of recurrent temporomandibular joint dislocation: a case report. J Oral Sci 2007;49:2379.

13. Candirli C, Yüce S, Cavus UY, Akin K, Cakir B. Autologous blood injection to the temporomandibular joint: magnetic resonance imaging findings. Imaging Sci Dent 2012;42:13-8. 